\title{
Global Asthma Research with Special Reference to India: A Scientometric Assessment of Publication Output during 2007-16
}

\author{
Gupta BM1, Jeevanjyot Kaur², Kiran Baidwan² and Ritu Gupta ${ }^{3 *}$ \\ ${ }^{1}$ FormerlyCSIR -NISTADS, New Delhi, 11012, India \\ ${ }^{2}$ Postgraduate Institute of Medical Education \& Research, India \\ ${ }^{3}$ FormerlySri Venkateshwara University, India
}

\section{Research Article}

Volume 3 Issue 1

Received Date: May 01, 2018

Published Date: May 18, 2018

*Corresponding author: Ritu Gupta, Sri Venkateshwara University, Andhra Pradesh, India; E-mail: ritu7648@gmail.com

\section{Abstract}

The paper examines 2094 Indian publications on asthma research, as covered in Scopus database during 2007-16, registering an annual average growth rate of $12.14 \%$, global share of $2.72 \%$, qualitative citation impact averaged to 10.857 citations per paper and international collaborative publication share of $13.51 \%$. The top 12 most productive countries individually contributed global share from $2.72 \%$ to $31.27 \%$, with largest global publication share coming from USA (31.27\%), followed by U.K. (10.45\%), Germany (5.60\%), Canada (5.44\%), etc. Together, the 12 most productive countries accounted for $83.80 \%$ share of global publication output during 2007-16.Medicine, among subjects, accounted for the highest publications share (61.32\%), followed by pharmacology, toxicology \& pharmaceutics (35.05\%) biochemistry, genetics \& molecular biology (20.25\%), immunology \& microbiology (7.78\%), agricultural \& biological sciences (3.44\%) and chemistry (2.88\%) and during 2007-16. Among different type of asthma, allergic asthma contributed the highest number of publications, followed by bronchial asthma, atopic asthma, occupational asthma and seasonal asthma, etc. during 2007-16.The top 15most productive organizations and authors together contributed 33.48\% and $19.96 \%$ respectively as their share of global publication output and $43.88 \%$ and $36.93 \%$ respectively as their share of global citation output during 2007-16. Among 2059 journal papers, the top 15 journals contributed 25.89\% share to the Indian journal output during 2007-16. Only 29 publications registered citations from 100 to 868 and received 6792 citations, with citations per paper of 234.21 .

Keywords: Asthma research; India; Publications; Citations; International Collaborative Papers; Scientometrics; Bibliometrics 


\section{Open Access Journal of Pulmonary \& Respiratory Sciences}

\section{Introduction}

Asthma is a disease of the bronchial tubes in the lungs (the "airways"). People with asthma typically experience "wheezing", a high-pitched whistling sound heard during breathing, especially when breathing out. However, wheezing does not always occur, and asthma can also involve breathlessness, chest tightness or coughing. The underlying process includes chronic inflammation of the airways, reversible obstruction of the flow of air in and out of the airways, and the tendency of the airways to over-react to stimuli [1].

There are two types of asthma depending on the type of trigger - extrinsic and intrinsic asthma. Extrinsic asthma is an immune response to an external allergen such as pollen, animal dander, dust, etc. Intrinsic asthma is caused due to inhaling certain chemical agents such as cigarette smoke, paint vapours, etc. In some cases it may also be worsened by a chest infection, stress, laughter etc. The most common allergens that cause asthma are pollen, dust, pollution like smoke from vehicles, animal dander, certain smells like that of diesel and petrol combustion, peeling paint and fungus in enclosed areas. There are mainly two types of reactions a delayed hypersensitive response (where the person experiences symptoms after a long period of time) and an instant hypersensitive response (where the person immediately develops symptoms to the allergen). Some drugs like aspirin and other NSAIDs are also known to cause asthma attacks [2].

Asthma most commonly develops in early childhood, and more than three-quarters of children who develop asthma symptoms before age 7 no longer have symptoms by age 16. However, asthma can develop at any stage in life, including adulthood. The current estimates of global burden of asthma: (i) 334 million people have asthma; (ii) $14 \%$ of the world's children experience asthma symptoms; (iii) $8.6 \%$ of young adults (aged 18-45) experience asthma symptoms; (iv) $4.5 \%$ of young adults have been diagnosed with asthma and/or are taking treatment for asthma; (v) The burden of asthma is greatest for children aged 10-14 and the elderly aged 7579 [1].

Asthma causes limitations in daily activities, loss of school and work days, lung function impairment, reduced quality of life, and an adverse socioeconomic burden. About 15 million disability-adjusted life years are lost annually due to asthma, which represents $1 \%$ of the total global disease burden. There are about 489,000 deaths attributable to asthma annually and the majority of deaths occur in low- and middle-income countries, particularly Oceania, South and Southeast Asia, the Middle East, and Africa [3]. Of 334 million people suffering from asthma worldwide, about one- tenth live in India. A recent Indian Study on Epidemiology of Asthma, Respiratory Symptoms and Chronic Bronchitis (INSEARCH) done with 85,105 men and 84,470 women from 12 urban and 11 rural sites in India estimated the prevalence of asthma in India to be $2.05 \%$ among those aged $>15$ years, with an estimated national burden of 18 million asthmatics [3].

\section{Literature Review}

Only a few studies have been published in this field. Among studies carried output, Klaewsongkram and Reantragoons [4] studied and analyzed asthma research from Asia-Pacific in the last decade by bibliometric method during 1998-2007, using PubMed database. Most of published asthma articles in Asia-Pacific are from affluent countries in northeast Asia and Oceania. Australia and Japan contributed more than half of regional articles on asthma. Emerging economies in Asia such as South Korea, Taiwan, Hong Kong, and Singapore, have dramatically increased in the last decade in terms of quantity and quality aspects and were considerable sources of basic and translational research in the region. Mainland China and India have significantly increased their research capacity as well, but quality needs to be improved New Zealand and Australia, countries with the highest asthma prevalence rates in the world, yielded highest citation counts per articles and were published in journals with high impact factor. Asthma research parameters per million population correlate well with gross domestic product per capita. Gupta and Bala [5] analyzed the research output of India in asthma during the period from 1999 till 2008. It analyzes the growth, rank and global publications share, citation impact, share of international collaborative papers, contribution of major collaborative partner countries and contribution of various subject fields. It also analyzes the characteristics of most productive institutions, authors and high-cited papers. Sweileh, Al-Jabi, Zyoud and Sawalha [6] analyzed research output (1304) originating from 22 Arab countries in the field of bronchial asthma and COPD, using Scopus database. Research productivity was evaluated based on: (a) total and trends of contribution of each Arab country to asthma and COPD research and (b) journals in which researchers from Arab countries published their research. Research output can be improved by investing more in international and national collaborative research projects in the field of asthma and COPD. In addition, bibliometric studies were also carried out on asthma in children and animal models in asthma. Chen, Chiu and Ho [7] evaluated the publication output associated with research on asthma in children during 1991-2002, Using

Ritu Gupta, et al. Global Asthma Research with Special Reference to India: A Scientometric Assessment of Publication Output during 2007-16. J Pulmon Respir Sci 2018, 3(1): 000116. 


\section{Open Access Journal of Pulmonary \& Respiratory Sciences}

SCI database. Parameters analyzed included language, type of document, page count, publication output, country of publication, authorship, publication pattern, and the most frequently cited paper. Börger, et al. [8] studied 3489 records connected to animal models of asthma from 52 countries during 1900-2006, the first being published in the year 1968. Assessing numbers of published items in relation to animal species it was found that mice were the preferred species followed by guinea pigs. There are also differences in the use of species. These differences are based on variations in the research focus as assessed by subject category analysis.

\section{Objectives}

The objectives of the present study are to study the performance of Indian asthma research during 2007-16, using on publications data indexed in Scopus database. In particular, the study analyzed the global research output and the research output of top 12 most productive countries, the growth of Indian research output, its global share and citation impact; the share of international collaboration publications in its India's output and significant contribution of foreign partner countries; distribution of the Indian research output by broad subject areas and the dynamics of its growth and decline, the distribution of Indian output by types of asthma, the productivity and citation impact of top 15 Indian most productive organizations and authors; the modes of communication and the characteristics of high cited papers.

\section{Methodology}

The asthma research publications landscape from 2007 through 2016 were identified using the Scopus database (http://www.scopus.com). An keyword search was used to identify publications that contained the terms "asthma" in the "Article title tag" or " keyword tags" or "source Title tag" and restricting it to the period 2007-16 in "date range tag" was used for searching the global publication data and this become the main search string. The search has resulted into 77118 publications on asthma research during 2007-16. The main search string with restricted to individual country name in "country tag", the publication data on individual top 10 most productive countries (including India) one by one was obtained. The Indian search string is further refined using provisions in Scopus database by "subject area tag", "country tag", "source title tag", "journal title name" and "affiliation tag", to get information on distribution of publications by subject, collaborating countries, author-wise, organization-wise and journal-wise, etc. Separate search strategies were also developed to get information on different type of asthma research. For citation data, citations to publications were also collected from date of publication till 19 April 2018. A number of bibliometric indicators (both absolute and relative) have been used in this study to measure the performance of asthma research in India.

(KEY (asthma) OR TITLE (asthma) OR SRCTITLE (asthma)) AND PUBYEAR > 2006 AND PUBYEAR < 2017 (KEY (asthma) OR TITLE (asthma) OR SRCTITLE (asthma)) AND PUBYEAR > 2006 AND PUBYEAR < 2017 AND (LIMIT-TO (AFFILCOUNTRY, "India "))

\section{Analysis}

The total research output of World and India's asthma research cumulated to 77118 and 2094 publications in 10 years during 2007-16, using a Scopus database. The annual global and Indian output in asthma research increased from 7004 and 98 in the year 2007 to 7953 and 238 publications in the year 2016, registering $1.48 \%$ and $12.14 \%$ growth per annum. The cumulative global and Indian output in asthma research computing in 5 years increased from 36994 and 834 during 2007-11 to 40124 and 1260 during 2012-16, registering growth rate of $8.46 \%$ and $51.08 \%$. India is ranked at $12^{\text {th }}$ position in global output and its global publication share in asthma research was $2.72 \%$ during 2007-16, which increased from $2.25 \%$ to $3.14 \%$ from $2007-11$ to $2012-16$. Of the total global publications output, $64.47 \%$ (1350) was published articles, $23.35 \%$ (489) as reviews, $5.40 \%$ (113) as letters, $2.20 \%(46)$ as editorials, $2.05 \%$ (43) as conference papers, $1.43 \%(30)$ as notes and the rest as book chapters (12), short surveys (9) and articles in press (2). The citation impact of Indian publications on asthma research averaged to 10.85 citations per publication (CPP) during 2007-16; five-yearly impact averaged to 17.17CPP for the period 2007-11 which declined to 6.67CPP in the succeeding five-year 2012-16 (Table 1). 


\section{Open Access Journal of Pulmonary \& Respiratory Sciences}

\begin{tabular}{|c|c|c|c|c|c|c|c|}
\hline & World & \multicolumn{7}{c|}{ India } \\
\hline & TP & TP & TC & CPP & \%TP & ICP & \%ICP \\
\hline 2007 & 7004 & 98 & 2629 & 26.83 & 1.4 & 10 & 10.2 \\
\hline 2008 & 7264 & 107 & 1954 & 18.26 & 1.47 & 13 & 12.15 \\
\hline 2009 & 7518 & 154 & 4436 & 28.81 & 2.05 & 20 & 12.99 \\
\hline 2010 & 7300 & 193 & 2297 & 11.9 & 2.64 & 22 & 11.4 \\
\hline 2011 & 7908 & 282 & 3004 & 10.65 & 3.57 & 31 & 10.99 \\
\hline 2012 & 8044 & 276 & 2214 & 8.02 & 3.43 & 32 & 11.59 \\
\hline 2013 & 8233 & 254 & 2137 & 8.41 & 3.09 & 27 & 10.63 \\
\hline 2014 & 7907 & 233 & 2551 & 10.95 & 2.95 & 42 & 18.03 \\
\hline 2015 & 7987 & 259 & 815 & 3.15 & 3.24 & 41 & 15.83 \\
\hline 2016 & 7953 & 238 & 690 & 2.9 & 2.99 & 45 & 18.91 \\
\hline $2007-11$ & 36994 & 834 & 14320 & 17.17 & 2.25 & 96 & 11.51 \\
\hline $2012-16$ & 40124 & 1260 & 8407 & 6.67 & 3.14 & 187 & 14.84 \\
\hline $2007-16$ & 77118 & 2094 & 22727 & 10.85 & 2.72 & 283 & 13.51 \\
\hline
\end{tabular}

Table 1: India's Output in Asthma Research during 2007-16.

\section{International Collaboration}

India's share of internationally collaborative papers (ICP) in asthma research was $13.51 \%$ during $2007-16$, which increased from $11.51 \%$ to $14.84 \%$ from $2007-11$ to 2012-16. Among the leading countries contributing to internationally collaborative papers, USA topped the list with $51.24 \%$ share, followed by U.K. (19.79\%), Australia (15.19\%), Germany (11.66\%), France, Netherland and
Sweden $(8.48 \%$ each), China (7.42\%), Switzerland (7.07\%) and Malaysia (6.71\%) during 2007-16. India's international collaborative publications share increased by $14.48 \%$ in USA, $3.85 \%$ in Malaysia, $1.77 \%$ in China and $1.24 \%$ in Switzerland, as against decrease by $12.39 \%$ in France, $9.15 \%$ in Germany, $6.08 \%$ in Netherlands, $4.51 \%$ in Sweden, $2.23 \%$ in Australia and $1.58 \%$ in U.K from 2007-11 to 2012-16 (Table 2).

\begin{tabular}{|c|c|c|c|c|c|c|c|}
\hline \multirow{2}{*}{ S.No } & Collaborative & \multicolumn{3}{|c|}{ Number of Papers } & \multicolumn{3}{c|}{ Share of Papers } \\
\cline { 3 - 8 } & Country & $\mathbf{2 0 0 7 - 1 1}$ & $\mathbf{2 0 1 2 - 1 6}$ & $\mathbf{2 0 0 7 - 1 6}$ & $\mathbf{2 0 0 7 - 1 1}$ & $\mathbf{2 0 1 2 - 1 6}$ & $\mathbf{2 0 0 7 - 1 6}$ \\
\hline 1 & USA & 40 & 105 & 145 & 41.67 & 56.15 & 51.24 \\
\hline 2 & U.K. & 20 & 36 & 56 & 20.83 & 19.25 & 19.79 \\
\hline 3 & Australia & 16 & 27 & 43 & 16.67 & 14.44 & 15.19 \\
\hline 4 & Germany & 17 & 16 & 33 & 17.71 & 8.56 & 11.66 \\
\hline 5 & France & 16 & 8 & 24 & 16.67 & 4.28 & 8.48 \\
\hline 6 & Netherlands & 12 & 12 & 24 & 12.5 & 6.42 & 8.48 \\
\hline 7 & Sweden & 11 & 13 & 24 & 11.46 & 6.95 & 8.48 \\
\hline 8 & China & 6 & 15 & 21 & 6.25 & 8.02 & 7.42 \\
\hline 9 & Switzerland & 6 & 14 & 20 & 6.25 & 7.49 & 7.07 \\
\hline 10 & Malaysia & 4 & 15 & 19 & 4.17 & 8.02 & 6.71 \\
\hline & Indian Total & 96 & 187 & 283 & & & \\
\hline
\end{tabular}

Table 2: Share of Leading Foreign Countries in India's Collaborative Research Output in Asthma Research during 200716.

\section{Top 12 Most Productive Countries in Asthma Research}

The global research output in the field asthma research had originated from as many as 165 countries in the world during 2007-16, of which 61 countries contributed each 1-10 papers, 52 countries each $11-100$ papers, 34 countries each 101-1000 papers, 15 countries each 10015000 papers and 1 country each 8060 and 24113 papers. Top 12 most productive countries in asthma research had 


\section{Open Access Journal of Pulmonary \& Respiratory Sciences}

contributed 2094 to 24113 publications each during 2007-16 (Table 3). Top 12 most productive countries in asthma research accounted for $83.80 \%$ global publication share during 2007-16. Their five-yearly output accounted for $82.17 \%$ global publication share during 2007-11which increased to $85.31 \%$ during succeeding 5 -year period 2012-16. Each of top 12 countries accounted for $2.72 \%$ to $31.27 \%$ global publication share during 2007-16, with USA accounting for the highest publication share
(31.27\%), followed by U.K (10.45\%), Germany and Canada (5.60\% and 5.44\%), Italy, China and Australia $(4.80 \%, 4.24 \%$ and $4.21 \%)$, etc. The global publication share in five years increased in China $(3.0 \%)$, India (0.89\%),Netherlands $(0.69 \%)$, Australia $(0.35 \%)$, Spain $(0.22 \%)$, USA $(0.16 \%)$, Japan $(0.04 \%)$ and Canada $(0.02 \%)$, but decreased in Germany (1.41\%), France $(0.52 \%)$, Italy $(0.25 \%)$ and U.K. (0.04\%) from $2007-11$ to 2012-16

\begin{tabular}{|c|c|c|c|c|c|c|c|}
\hline \multirow{2}{*}{ S.No } & \multirow{2}{*}{ Name of the Country } & \multicolumn{3}{|c|}{ Number of Papers } & \multicolumn{3}{c|}{ Share of Papers } \\
\cline { 3 - 8 } & & $\mathbf{2 0 0 7 - 1 1}$ & $\mathbf{2 0 1 2 - 1 6}$ & $\mathbf{2 0 0 7 - 1 6}$ & $\mathbf{2 0 0 7 - 1 1}$ & $\mathbf{2 0 1 2 - 1 6}$ & $\mathbf{2 0 0 7 - 1 6}$ \\
\hline 1 & USA & 11537 & 12576 & 24113 & 31.19 & 31.34 & 31.27 \\
\hline 2 & U.K. & 3875 & 4185 & 8060 & 10.47 & 10.43 & 10.45 \\
\hline 3 & Germany & 2342 & 1973 & 4315 & 6.33 & 4.92 & 5.6 \\
\hline 4 & Canada & 2010 & 2188 & 4198 & 5.43 & 5.45 & 5.44 \\
\hline 5 & Italy & 1823 & 1877 & 3700 & 4.93 & 4.68 & 4.8 \\
\hline 6 & China & 990 & 2276 & 3266 & 2.68 & 5.67 & 4.24 \\
\hline 7 & Australia & 1488 & 1756 & 3244 & 4.02 & 4.38 & 4.21 \\
\hline 8 & Japan & 1538 & 1683 & 3221 & 4.16 & 4.19 & 4.18 \\
\hline 9 & France & 1550 & 1472 & 3022 & 4.19 & 3.67 & 3.92 \\
\hline 10 & Spain & 1264 & 1461 & 2725 & 3.42 & 3.64 & 3.53 \\
\hline 11 & Netherlands & 1146 & 1521 & 2667 & 3.1 & 3.79 & 3.46 \\
\hline 12 & India & 834 & 1260 & 2094 & 2.25 & 3.14 & 2.72 \\
\hline & Total & 30397 & 34228 & 64625 & 82.17 & 85.31 & 83.8 \\
\hline & World & 36994 & 40124 & 77118 & & & \\
\hline & Share of 12 Countries in & \multirow{2}{*}{82.17} & 85.31 & \multirow{2}{*}{83.8} & & & \\
\hline
\end{tabular}

Table 3: Global Publication Output and Share of Top 12 Most Productive Countries in Asthma Research during 2007-16.

\section{Subject-Wise Distribution of Research Output}

The Indian asthma research output published during 2007-16 is distributed across five sub-fields (as identified in Scopus database classification), with medicine accounting for the highest publications share $(61.32 \%)$, followed by pharmacology, toxicology \& pharmaceutics (35.05\%) biochemistry, genetics \& molecular biology (20.25\%), immunology \& microbiology (7.78\%), agricultural \& biological sciences (3.44\%) and chemistry (2.88\%) and during 2007-16. The activity index, which computes change in research activity in a discipline over time 2007-11 to 2012-16 (world average activity index of a given subject is taken as 100), witnessed increase in biochemistry, genetics \& molecular biology (from 82.31 to 111.71 ) and chemistry (from 96.57 to 102.27), as against decrease in medicine (from 106.18 to 95.91), pharmacology, toxicology \& pharmaceutics (from 102.28 to 98.49), immunology \& microbiology (from 100.12 to 99.92) and agricultural \& biological sciences (from 108.10 to 94.64) from 2007-11 to 2012-16. Immunology \& microbiology, among five subjects registered the highest citation impact per paper (19.10), followed by biochemistry, genetics \& molecular biology (12.53), agricultural \& biological sciences (12.33), medicine (11.05), chemistry (9.31) and pharmacology, toxicology \& pharmaceutics (8.76) during 2007-16 (Table 4).

\begin{tabular}{|c|c|c|c|c|c|c|c|c|c|}
\hline \multirow{2}{*}{ S.No } & \multirow{2}{*}{ Subject* } & \multicolumn{2}{|c|}{ Number of Papers (TP) } & \multicolumn{2}{c|}{ Activity Index } & TC & CPP & \%TP \\
\cline { 3 - 10 } & 2007-11 & $\mathbf{2 0 1 2 - 1 6}$ & $\mathbf{2 0 0 7 - 1 6}$ & $\mathbf{2 0 0 7 - 1 1}$ & $\mathbf{2 0 1 2 - 1 6}$ & $\mathbf{2 0 0 7 - 1 6}$ & $\mathbf{2 0 0 7 - 1 6}$ & $\mathbf{2 0 0 7 - 1 6}$ \\
\hline 1 & Medicine & 543 & 741 & 1284 & 106.18 & 95.91 & 14192 & 11.05 & 61.32 \\
\hline 2 & $\begin{array}{c}\text { Pharmacology, } \\
\text { Toxicology \& } \\
\text { Pharmaceutics }\end{array}$ & 299 & 435 & 734 & 102.28 & 98.49 & 6428 & 8.76 & 35.05 \\
\hline
\end{tabular}

Ritu Gupta, et al. Global Asthma Research with Special Reference to India: A Scientometric Assessment of Publication Output during 2007-16. J Pulmon Respir Sci 2018, 3(1): 000116. 


\section{Open Access Journal of Pulmonary \& Respiratory Sciences}

\begin{tabular}{|c|c|c|c|c|c|c|c|c|c|}
\hline 2 & $\begin{array}{c}\text { Biochemistry, } \\
\text { Genetics \& } \\
\text { Molecular Biology }\end{array}$ & 139 & 285 & 424 & 82.31 & 111.71 & 5313 & 12.53 & 20.25 \\
\hline 3 & $\begin{array}{c}\text { Immunology \& } \\
\text { Microbiology }\end{array}$ & 65 & 98 & 163 & 100.12 & 99.92 & 3114 & 19.1 & 7.78 \\
\hline 4 & $\begin{array}{c}\text { Agricultural \& } \\
\text { Biological Sciences }\end{array}$ & 31 & 41 & 72 & 108.1 & 94.64 & 888 & 12.33 & 3.44 \\
\hline 5 & Chemistry & 20 & 32 & 52 & 96.57 & 102.27 & 484 & 9.31 & 2.48 \\
\hline \multicolumn{8}{|c|}{ TP=Total Papers; TC=Total Citations; CPP=Citations Per Paper } \\
\hline
\end{tabular}

Table 4: Subject-Wise Breakup of Indian Publications in Asthma Research in India during 2007-16.

\section{Break up of Publications by Type of Asthma}

On classifying Indian asthma research output by type of asthma, it was observed that the largest number of publications were in allergic asthma (317 papers), followed by bronchial asthma (228 papers), atopic asthma (43 papers), occupational asthma and seasonal asthma (42 papers each), nocturnal asthma (36 papers), acute severe asthma (20 papers), exercise induced asthma and adult-onset asthma (11 papers each), aspirin induced asthma (9 papers), child onset asthma ( 7 papers) and alcohol induced asthma (2 papers) during 2007-16. In terms of global publication share, acute severe asthma registered the highest share (6.69\%), followed by nocturnal asthma (6.59\%), by bronchial asthma (3.97\%), alcohol induced asthma (2.60\%), allergic asthma (2.38\%), seasonal asthma (2.25\%), adult-onset asthma (1.87\%), aspirin induced asthma (1.75\%), occupational asthma $(1.59 \%)$, child onset asthma $(1.40 \%)$ and atopic asthma (1.14\%) during 2007-16. The global publication share has increased in allergic asthma (from 1.93\% to 2.80\%), bronchial asthma (from $2.55 \%$ to $5.62 \%$ ), atopic asthma (from $0.95 \%$ to $1.31 \%$ ), occupational asthma (from $1.03 \%$ to $2.18 \%$ ), seasonal asthma (from $1.94 \%$ to $2.65 \%$ ), nocturnal asthma (from $4.82 \%$ to $9.35 \%$ ), exercise induced asthma (from $1.01 \%$ to $1.18 \%$ ), aspirin induced asthma (from $1.64 \%$ to $1.85 \%$ ), child onset asthma (from $0.90 \%$ to $1.81 \%$ ) as against decrease in acute severe asthma (from $7.04 \%$ to $6.37 \%$ ), adult onset asthma (from $2.16 \%$ to $1.69 \%$ ) and alcohol induced asthma (from $6.67 \%$ to $0 \%$ ) from $2007-11$ to $2012-16$.

\begin{tabular}{|c|c|c|c|c|c|c|c|c|c|c|c|}
\hline \multirow{2}{*}{ S.No } & \multirow{2}{*}{ Type of Asthma } & \multicolumn{3}{|c|}{ World } & \multicolumn{3}{c|}{ India } & \multicolumn{3}{c|}{ \% India } \\
\cline { 3 - 12 } & $2006-11$ & $2012-16$ & $2007-16$ & $2006-11$ & $2012-16$ & $2007-16$ & $2006-11$ & $2012-16$ & $2007-16$ \\
\hline 1 & Allergic Asthma & 7363 & 7822 & 15185 & 142 & 219 & 361 & 1.93 & 2.8 & 2.38 \\
\hline 2 & Bronchial Asthma & 3096 & 2653 & 5749 & 79 & 149 & 228 & 2.55 & 5.62 & 3.97 \\
\hline 3 & Atopic Asthma & 1786 & 1991 & 3777 & 17 & 26 & 43 & 0.95 & 1.31 & 1.14 \\
\hline 4 & $\begin{array}{c}\text { Occupational } \\
\text { Asthma }\end{array}$ & 1356 & 1282 & 2638 & 14 & 28 & 42 & 1.03 & 2.18 & 1.59 \\
\hline 5 & Seasonal Asthma & 1033 & 831 & 1864 & 20 & 22 & 42 & 1.94 & 2.65 & 2.25 \\
\hline 6 & Nocturnal Asthma & 332 & 214 & 546 & 16 & 20 & 36 & 4.82 & 9.35 & 6.59 \\
\hline 7 & $\begin{array}{c}\text { Acute Severe } \\
\text { Asthma }\end{array}$ & 142 & 157 & 299 & 10 & 10 & 20 & 7.04 & 6.37 & 6.69 \\
\hline 8 & $\begin{array}{c}\text { Exercise Induced } \\
\text { Asthma }\end{array}$ & 596 & 424 & 1020 & 6 & 5 & 11 & 1.01 & 1.18 & 1.08 \\
\hline 9 & $\begin{array}{c}\text { Adult-Onset } \\
\text { Asthma }\end{array}$ & 231 & 356 & 587 & 5 & 6 & 11 & 2.16 & 1.69 & 1.87 \\
\hline 10 & $\begin{array}{c}\text { Aspirin Induced } \\
\text { Asthma }\end{array}$ & 244 & 270 & 514 & 4 & 5 & 9 & 1.64 & 1.85 & 1.75 \\
\hline 11 & $\begin{array}{c}\text { Child Onset } \\
\text { Asthma }\end{array}$ & 222 & 277 & 499 & 2 & 5 & 7 & 0.9 & 1.81 & 1.4 \\
\hline 12 & $\begin{array}{c}\text { Alcohol Induced } \\
\text { Asthma }\end{array}$ & 30 & 47 & 77 & 2 & 0 & 2 & 6.67 & 0 & 2.6 \\
\hline
\end{tabular}

Table 5: Breakup of Global and Indian Publications by Type of Asthma, 2007-16.

Ritu Gupta, et al. Global Asthma Research with Special Reference to India: A Scientometric

Assessment of Publication Output during 2007-16. J Pulmon Respir Sci 2018, 3(1): 000116. 


\section{Open Access Journal of Pulmonary \& Respiratory Sciences}

\section{Profile of Top 15 Most Productive Indian Organizations}

In Indian asthma research, the productivity of 15 most productive organizations varied from 18 to 142 publications and together they contributed $33.48 \%$ (701) publication share and $43.88 \%$ (9972) citation share to its cumulative publications output during 2007-16. The scientometric profile of these 15 organizations is presented in Table 6.

a) Five of these organizations registered publications output greater than the group average of 46.73: Post graduate Institute of Medical Education \& Research, Chandigarh (142 papers), Institute of Genomics \& Integrated Biology, Delhi (98 papers), University of Delhi (88 papers), All India Institute of Medical Sciences New Delhi (87 papers) and Vallabhai Patel Chest Institute, Delhi (51 papers) during 2007-16.

b) Six organizations registered impact above the group average of 14.23citations per publication during 200716: University of Delhi (20.72), Jamia Hamdard University, Delhi (20.04), Dr Harisingh Gour University, Sagar (18.80), University of Pune (18.32), Institute of Genomics \& Integrated Biology, Delhi (17.96) and All India Institute of Medical Sciences, New Delhi (17.14) during 2007-16. c) Five organizations registered h-index above the group average of 11.53: Institute of Genomics \& Integrated Biology, Delhi (23), Postgraduate Institute of Medical Education \& Research, Chandigarh (20), All India Institute of Medical Sciences, New Delhi (19), University of Delhi (17) and Vallabhai Patel Chest Institute, Delhi (14) during 2007-16.

d) Eight organizations contributed international collaborative publications share above the group average of 9.27\%: Kasturba Medical College, Manipal (16.0\%), Institute of Genomics \& Integrated Biology, Delhi (15.31\%), University of Delhi (14.77\%), Vallabhai Patel Chest Institute, Delhi (13.73\%), Jamia Hamdard University, Delhi (13.04\%), Indian Institute of Toxicological Research, Lucknow (11.11\%), All India Institute of Medical Sciences, New Delhi (10.34\%) and Panjab University, Chandigarh (9.52\%) during 200716.

e) Six organizations registered the relative citation index above the group average (1.31) of all organizations: University of Delhi (1.91) Jamia Hamdard University, Delhi (1.85), Dr. Harisingh Gour University, Sagar (1.73), University of Pune (1.69), Institute of Genomics \& Integrated Biology, Delhi (1.66) and All India Institute of Medical Sciences, New Delhi (1.58) during 2007-16

\begin{tabular}{|c|c|c|c|c|c|c|c|c|}
\hline S.No & Name of the Organization & TP & TC & CPP & HI & ICP & \%ICP & RCI \\
\hline 1 & $\begin{array}{c}\text { Postgraduate Institute of Medical } \\
\text { Education \& Research (PGIMER), } \\
\text { Chandigarh }\end{array}$ & 142 & 1721 & 12.12 & 20 & 8 & 5.63 & 1.12 \\
\hline 2 & $\begin{array}{c}\text { Institute of Genomics \& Integrated } \\
\text { Biology (IGIB), Delhi }\end{array}$ & 98 & 1760 & 17.96 & 23 & 15 & 15.3 & 1.66 \\
\hline 3 & University of Delhi & 88 & 1823 & 20.72 & 17 & 13 & 14.8 & 1.91 \\
\hline 4 & $\begin{array}{c}\text { All India Institute of Medical Sciences } \\
\text { (AIIMS), New Delhi }\end{array}$ & 87 & 1491 & 17.14 & 19 & 9 & 10.3 & 1.58 \\
\hline 5 & $\begin{array}{c}\text { Vallabhai Patel Chest Institute (VPCI), } \\
\text { Delhi }\end{array}$ & 51 & 716 & 14.04 & 14 & 7 & 13.7 & 1.29 \\
\hline 6 & $\begin{array}{c}\text { ChhatrapatiShahijiMaharaj Medical } \\
\text { University, Lucknow }\end{array}$ & 37 & 229 & 6.19 & 9 & 1 & 2.7 & 0.57 \\
\hline 7 & $\begin{array}{c}\text { Sanjay Gandhi Postgraduate Institute of } \\
\text { Medical Sciences (SGPGIMS),Lucknow }\end{array}$ & 26 & 241 & 9.27 & 8 & 1 & 3.85 & 0.85 \\
\hline 8 & $\begin{array}{c}\text { Kasturba Medical College (KMC), } \\
\text { Manipal }\end{array}$ & 25 & 60 & 2.4 & 4 & 4 & 16 & 0.22 \\
\hline 9 & $\begin{array}{c}\text { Banaras Hindu University (BHU), } \\
\text { Varanasi }\end{array}$ & 24 & 173 & 7.21 & 7 & 0 & 0 & 0.66 \\
\hline 10 & JamiaHamdard University, Delhi & 23 & 461 & 20.04 & 9 & 3 & 13 & 1.85 \\
\hline 11 & Saveetha Dental College & 22 & 43 & 1.95 & 4 & 0 & 0 & 0.18 \\
\hline 12 & Panjab University, Chandigarh & 21 & 293 & 13.95 & 8 & 2 & 9.52 & 1.29 \\
\hline 13 & DrHarisinghGour University, Sagar & 20 & 376 & 18.8 & 10 & 0 & 0 & 1.73 \\
\hline 14 & University of Pune & 19 & 348 & 18.32 & 11 & 0 & 0 & 1.69 \\
\hline 15 & Indian Institute of Toxicological & 18 & 237 & 13.17 & 10 & 2 & 11.1 & 1.21 \\
\hline
\end{tabular}

Ritu Gupta, et al. Global Asthma Research with Special Reference to India: A Scientometric Assessment of Publication Output during 2007-16. J Pulmon Respir Sci 2018, 3(1): 000116. 


\section{Open Access Journal of Pulmonary \& Respiratory Sciences}

\begin{tabular}{|c|c|c|c|c|c|c|c|c|}
\hline & Research (IITR), Lucknow & & & & & \\
\hline & Total of 15 organizations & 701 & 9972 & 14.23 & 12 & 65 & 9.27 & 1.31 \\
\hline & Total of India & 2094 & 22727 & 10.85 & & & & \\
\hline & $\begin{array}{l}\text { Share of top 15 organizations in India } \\
\text { total output }\end{array}$ & 33.5 & 43.88 & & & & & \\
\hline
\end{tabular}

Table 6: Scientometric Profile of Top 15 Most Productive Organizations in Asthma Research in India during 2007-16.

\section{Profile of Top 15 Most Productive Authors}

In Indian asthma research, the productivity of 15 most productive top 15 most productive authors varied from 18to 53 publications. Together they contributed 19.96\% (418) publication share and $36.93 \%$ (8392) citation share during 2007-16. The scientometric profile of these 15authors is presented in (Table 7).

a) Four authors registered publications output above the group average of 27.87: B. Ghosh (53 papers), R. Agarwal (52 papers), A. Agrawal (41 papers) and U. Mabalirajan (33 papers) during 2007-16.

b) Seven authors registered impact above the group average of 20.78 citations per publication: T. Ahmad (35.85), U. Mabalirajan (29.94), D. Gupta (29.58), A. Chakrabarti (28.85), B. Ghosh (24.62), R. Agarwal 924.38) and A. Agrawal (21.78) during 2007-16. c) Eight authors achieved h-index above the group average of 12.2: B. Ghosh (21), U. Mabalirajan (19), R. Agarwal (17), A. Agrawal (16), T. Ahmad, D. Gupta and A.N. Aggarwal (15 each) and A. Chakrabarti (14) during 2007-16.

d) Six authors contributed international collaborative publications share above the group average of $7.66 \%$ of all authors: U. Mabalirajan (18.18\%), A. Agrawal (17.07\%), P.A. Mamesh (16.67\%), B. Ghosh (15.09\%), T. Ahmad and A. Chakrabarti (10\% each)

e) Seven authors registered the relative citation index above the group average (1.85) of all authors: T. Ahmad (3.30), U. Mabalirajan (2.76), D. Gupta (2.73), A. Chakrabarti (2.38), B. Ghosh (2.27), R. Agarwal (2.25) and A. Agrawal (2.01) during 2007-16.

\begin{tabular}{|c|c|c|c|c|c|c|c|c|c|}
\hline S.No & $\begin{array}{c}\text { Name of the } \\
\text { Author }\end{array}$ & Affiliation of the Author & TP & TC & CPP & HI & ICP & \%ICP & RCI \\
\hline 1 & B. Ghosh & $\begin{array}{c}\text { Institute of Genomics \& Integrated Biology (IGIB), } \\
\text { Delhi }\end{array}$ & 53 & 1305 & 25 & 21 & 8 & 15.1 & 2.27 \\
\hline 2 & R. Agarwal & $\begin{array}{c}\text { Postgraduate Institute of Medical Education \& } \\
\text { Research (PGIMER), Chandigarh }\end{array}$ & 52 & 1268 & 24 & 17 & 2 & 3.85 & 2.25 \\
\hline 3 & A. Agrawal & $\begin{array}{c}\text { Institute of Genomics \& Integrated Biology (IGIB), } \\
\text { Delhi }\end{array}$ & 41 & 893 & 22 & 16 & 7 & 17.1 & 2.01 \\
\hline 4 & U. Mabalirajan & $\begin{array}{c}\text { Institute of Genomics \& Integrated Biology (IGIB), } \\
\text { Delhi }\end{array}$ & 33 & 988 & 30 & 19 & 6 & 18.2 & 2.76 \\
\hline 5 & S. Awasthi & $\begin{array}{c}\text { ChhatrapatiShahijiMaharaj } \\
\text { Medical University, Lucknow }\end{array}$ & 27 & 148 & 5.5 & 8 & 1 & 3.7 & 0.51 \\
\hline 6 & D. Gupta & Vallabhai Patel Chest Institute (VPCI), Delhi & 26 & 769 & 30 & 15 & 1 & 3.85 & 2.73 \\
\hline 7 & A.N. Aggarwal & $\begin{array}{c}\text { Postgraduate Institute of Medical Education \& } \\
\text { Research (PGIMER), Chandigarh }\end{array}$ & 27 & 535 & 20 & 15 & 0 & 0 & 1.83 \\
\hline 8 & S.N. Gour & Vallabhai Patel Chest Institute (VPCI), Delhi & 24 & 357 & 15 & 3 & 0 & 0 & 1.37 \\
\hline 9 & N. Arora & $\begin{array}{c}\text { Institute of Genomics \& Integrated Biology (IGIB), } \\
\text { Delhi }\end{array}$ & 21 & 271 & 13 & 11 & 0 & 0 & 1.19 \\
\hline 10 & T. Ahmad & $\begin{array}{c}\text { Institute of Genomics \& Integrated Biology (IGIB), } \\
\text { Delhi }\end{array}$ & 20 & 717 & 36 & 15 & 2 & 10 & 3.3 \\
\hline 11 & A. Chakrabarti & $\begin{array}{c}\text { Postgraduate Institute of Medical Education \& } \\
\text { Research (PGIMER), Chandigarh }\end{array}$ & 20 & 517 & 26 & 14 & 2 & 10 & 2.38 \\
\hline 12 & S.K. Kabra & $\begin{array}{c}\text { All India Institute of Medical Sciences (AIIMS), } \\
\text { New Delhi }\end{array}$ & 19 & 112 & 5.9 & 7 & 0 & 0 & 0.54 \\
\hline
\end{tabular}

Ritu Gupta, et al. Global Asthma Research with Special Reference to India: A Scientometric Assessment of Publication Output during 2007-16. J Pulmon Respir Sci 2018, 3(1): 000116 


\section{Open Access Journal of Pulmonary \& Respiratory Sciences}

\begin{tabular}{|c|c|c|c|c|c|c|c|c|c|}
\hline 13 & B.P. Sing & $\begin{array}{c}\text { Institute of Genomics \& Integrated Biology (IGIB), } \\
\text { Delhi }\end{array}$ & 19 & 267 & 14 & 12 & 0 & 0 & 1.3 \\
\hline 14 & R. Lodha & $\begin{array}{c}\text { All India Institute of Medical Sciences (AIIMS), } \\
\text { New Delhi }\end{array}$ & 18 & 102 & 5.7 & 6 & 0 & 0 & 0.52 \\
\hline 15 & P.A. Mamesh & Cheluvamba Hospital, Mysore & 18 & 143 & 7.9 & 7 & 3 & 16.7 & 0.73 \\
\hline $\begin{array}{c}\text { Total of 15 } \\
\text { authors } \\
\text { Total of India }\end{array}$ & 418 & 8392 & 20 & 12 & 32 & 7.66 & 1.85 \\
\hline $\begin{array}{c}\text { Share of top 15 } \\
\text { authors in Indian } \\
\text { total output }\end{array}$ & 2094 & 22727 & 11 & & & & \\
\hline $\begin{array}{r}\text { TP=Total Papers; TC=Total Citations; CPP=Citations Per Paper; HI=h-index; ICP=International Collaborative Papers; } \\
\text { RCI=Relative Citation Index }\end{array}$ & 20 & 36.93 & & & & \\
\hline
\end{tabular}

Table 7: Scientometric Profile of Top 15 Most Productive Authors in Asthma Research in India during 2007-16.

\section{Medium of Communication}

Of the total Indian publications output in asthma research, 98.33\% (2059) appeared in journals. The top 15 most productive journals accounted for 20 to 67 papers each in asthma research and together accounted for $25.89 \%$ share (533 papers) of total journal publication output during 2007-16. The publication share of these top 15 most productive journals increased from $22.16 \%$ to
27.90\% between 2007-11 and 2012-16. The top most productive journal (with 67 papers) was Lung India, followed by Indian Journal of Pharma \& Bio Sciences (57 papers), Indian Journal of Pediatrics (44 papers), Research Journal of Pharmaceutical Biological \& Chemical Sciences (42 papers), International Journal of Pharmacy \& Pharmaceutical Sciences (41 papers each), etc. during 2007-16 (Table 8).

\begin{tabular}{|c|c|c|c|c|}
\hline \multirow{2}{*}{ S.No } & Name of the Journal & \multicolumn{3}{c|}{ Number of Papers } \\
\cline { 2 - 5 } & Lung India & $2007-11$ & $\mathbf{2 0 1 2 - 1 6}$ & $\mathbf{2 0 0 7 - 1 6}$ \\
\hline 1 & Indian Journal of Pharma \& Bio Sciences & 47 & 67 \\
\hline 2 & Indian Journal of Pediatrics & 13 & 44 & 57 \\
\hline 3 & Research Journal of Pharmaceutical Biological \& Chemical Sciences & 9 & 25 & 44 \\
\hline 4 & International Journal of Pharmacy \& Pharmaceutical Sciences & 9 & 33 & 42 \\
\hline 5 & Journal of Clinical \& Diagnostic Research & 9 & 29 & 38 \\
\hline 6 & Indian Pediatrics & 16 & 19 & 35 \\
\hline 7 & Asian Journal of Pharmaceutical \& Clinical Research & 8 & 26 & 34 \\
\hline 8 & Journal of Ethno-pharmacology & 11 & 23 & 34 \\
\hline 9 & Jnternal of Asthma & 13 & 14 & 27 \\
\hline 10 & Research Journal of Pharmacy \& Technology & 9 & 17 & 26 \\
\hline 11 & Indian Journal of Medical Research & 7 & 17 & 24 \\
\hline 12 & International Journal of Pharmtech Research & 7 & 16 & 23 \\
\hline 13 & International Journal of Research in Ayurveda \& Pharmacy & 10 & 11 & 21 \\
\hline 14 & Total of 15 journals & 0 & 20 & 20 \\
\hline 15 & Total India journal output & 760 & 373 & 533 \\
\hline & Share of top 15 journals in Indian journal output & 22.16 & 27.9 & 25.9 \\
\hline
\end{tabular}

Table 8: Top 15 Most Productive Journals in Asthma Research in India during 2007-16.

\section{High Cited Papers}

Only $29(1.38 \%)$ of total 2094 papers in asthma research in India received 100 to 868 citations each since their publication during 2007-16. These 29 high cited papers were contributed by 801 authors from 585 organizations across 62 countries; together they received 6792 citations, and averaged 234.21 citations per paper. The research productivity among foreign participating 


\section{Open Access Journal of Pulmonary \& Respiratory Sciences}

countries in high cited papers was the largest from U.K. (16 papers), Germany and France (10 papers each), USA and Sweden (9 papers each), Australia and Netherlands (8 papers each), Chile and Hong Kong (7 papers each), Brazil, Spain and New Zealand (6 papers each), Norway and South Africa (5 papers each), Malta, Thailand, Peru and Kenya (4 papers each), etc. Amongst 29 highly cited papers, 12 were reviews and 17 articles. Among 29 high cited papers, 11 resulted from solo organizations per paper, and 18 from 2 or more organizations per paper 1 national collaborative and 17 international collaborative paper). The most significant Indian organizations participating (among 31) in high cited papers were: Jaslok Hospital \& Research Center, Mumbai (5 papers), Chest Research Foundation, Pune (3 papers), PGIMERChandigarh and AIIMS-New Delhi (2 papers each) and 1 paper each by 28 other Indian organizations.

The 29 highly cited papers were published in 21 journals, with 4 papers in The Lancet, followed by 2 papers each in Allergy: European Journal of Allergy \& Clinical Immunology, International Journal of Pharmaceutics, Journal of Allergy \& Clinical Immunology, The Lancet Respiratory Medicine, New England Journal of Medicine, and Thorax, and 1 paper each in 13 other journals: Asia Pacific Journal of Biomedical Sciences, Bulletin of WHO, Chest, Clinical \& Experimental Allergy, European Journal of Medicinal Chemistry, European Journal of Pediatrics, European Journal of Pharmacology, Intensive Care Medicine, Journal of Ethnopharmacology, Journal of Medicinal Chemistry, Pediatric Respiratory Review, Oxidative Medicine \& Cellular Longevity, Pediatric Allergy \& Immunology and Pharmacology.

\section{Summary \& Conclusion}

\section{Summary}

India had produced 2094 publications on asthma research as indexed in Scopus database in 10 years during 2007-16, which increased from 98 to 238 from the year 2007 to year 2016, registering $12.14 \%$ annual growth. India's global publications rank was $12^{\text {th }}$ and its global share was $2.72 \%$ during 2007-16, which increased from $2.25 \%$ to $3.14 \%$ from $2007-11$ to $2012-16$. India's citation impact per paper averaged to 10.85 during 2007-16, which dropped from 17.17 to 6.67 from $2007-11$ to 2012 16. The share of international collaborative papers of India in its research output on asthma research was $13.51 \%$ during $2007-16$, which increased from $11.51 \%$ to $14.84 \%$ from 2007-11 to 2012-16. Medicine, among subjects, accounted for the highest publications share $(61.32 \%)$, followed by pharmacology, toxicology \& pharmaceutics (35.05\%) biochemistry, genetics \& molecular biology (20.25\%), immunology \& microbiology (7.78\%), agricultural \& biological sciences $(3.44 \%)$ and chemistry (2.88\%) and during 2007-16. Among different type of asthma, allergic asthma contributed the highest number of publications, followed by bronchial asthma, atopic asthma, occupational asthma and seasonal asthma, etc. during 2007-16.

The top 15 most productive organizations and authors together contributed $33.48 \%$ and $19.96 \%$ respectively as their share of global publication output and $43.88 \%$ and $36.93 \%$ respectively as their share of global citation output during 2007-16. The leading most productive Indian organizations contributing to asthma research were Postgraduate Institute of Medical Education \& Research, Chandigarh (142 papers), Institute of Genomics \& Integrated Biology, Delhi (98 papers), University of Delhi (88 papers), All India Institute of Medical Sciences New Delhi (87 papers), Vallabhai Patel Chest Institute, Delhi (51 papers), etc. during 2007-16. The leading Indian organizations with comparatively higher citation impact per paper were University of Delhi (20.72), Jamia Hamdard University, Delhi (20.04), Dr Harisingh Gour University, Sagar (18.80), University of Pune (18.32), Institute of Genomics \& Integrated Biology, Delhi (17.96), All India Institute of Medical Sciences, New Delhi (17.14) etc. during 2007-16. The leading most productive authors contributing to Indian asthma research were B. Ghosh (53 papers), R. Agarwal (52 papers), A. Agrawal (41 papers), U. Mabalirajan (33 papers) etc. during 2007-16. The leading Indian authors with comparatively higher citation impact per paper were T. Ahmad (35.85), U. Mabalirajan (29.94), D. Gupta (29.58), A. Chakrabarti (28.85), B. Ghosh (24.62), R. Agarwal 924.38), A. Agrawal (21.78) etc. during 2007-16.

Of the 2059 journal publications from India on asthma, the top 15 most productive journals accounted for $25.89 \%$ share of total Indian journal publication output during 2007-16, which increased from $22.16 \%$ to $27.90 \%$ between 2007-11 and 2012-16. The top most productive journal was Lung India (67 papers), followed by Indian Journal of Pharma \& Bio Sciences (57 papers), Indian Journal of Paediatrics (44 papers), Research Journal of Pharmaceutical Biological \& Chemical Sciences $(42$ papers), International Journal of Pharmacy \& Pharmaceutical Sciences (41 papers each), etc. during 2007-16. Twenty nine papers have been identified as high cited, which received 100 to 868 citations; together they received 6792 citations, and averaged 234.21 citations per paper. These 29 high cited papers were contributed by 801 authors from 585 organizations across 62 countries. U.K. registered the highest participation $(16$

Ritu Gupta, et al. Global Asthma Research with Special Reference to India: A Scientometric Assessment of Publication Output during 2007-16. J Pulmon Respir Sci 2018, 3(1): 000116. 


\section{Open Access Journal of Pulmonary \& Respiratory Sciences}

papers) in high cited papers, followed by Germany and France (10 papers each), USA and Sweden ( 9 papers each), Australia and Netherlands (8 papers each), Chile and Hong Kong (7 papers each), Brazil, Spain and New Zealand ( 6 papers each), etc. The 29 highly cited papers were published in 21 journals, with 4 papers in The Lancet, followed by 2 papers each in Allergy: European Journal of Allergy \& Clinical Immunology, International Journal of Pharmaceutics, Journal of Allergy \& Clinical Immunology, The Lancet Respiratory Medicine, New England Journal of Medicine and Thorax and 1 paper each in 13 other journals.

\section{Conclusion}

The Indian research output in asthma research is very small and also registered much lower citation impact compared to developed countries. In view of very large prevalence and mortality from asthma cases in India, the research efforts in the country are much less. Therefore, there is argent need to scale up the existing R\&D efforts, both in terms of investment and involvement of more qualified and trained personnel. In addition, the government should invest more and encourage scientists to get involved in international collaborative projects and increase bilateral collaborative projects with leading countries in this area. Efforts should be made to recognize asthma as a disease of major public health importance. The national efforts should be made to increase public awareness of the disease to make sure patients and health professionals, recognise the disease and are aware of the severity of associated problems; organise and co-ordinate global epidemiological surveillance to monitor global and regional trends in asthma; develop and implement an optimal strategy for its management and prevention and stimulate research into the causes of asthma to develop new control strategies and treatment. In addition, India needs: (a) An up-to-date approach to the diagnosis and management of wheezing in young children, (b) Provide guaranteed access to quality-assured essential asthma medicines, (c) Provide effective policy action on known, remediable causes of asthma such as parental smoking (for children) and occupational exposures (for adults), (d) Increased capacity building of trained health professionals. This is vital and can be enabled by participation in research. Short courses in research generally, or asthma research in particular, provide opportunities for 'up- skilling' in research for those with limited time and resources.

\section{References}

1. The Global Asthma Report 2014. Auckland, New Zealand: Global Asthma Network, 2014. http://www.globalasthmareport.org/resources/Glob al_Asthma_Report_2014.pdf (Accessed on 28 April 2018)

2. Sampath, Pavitra. 10 facts about asthma you should know. $\quad 5 \quad$ May 2015. http://www.thehealthsite.com/diseases_conditions/ world-asthma-day-2013-10-facts-about-asthma-youshould-know/(Accessed on 28 April 2018)

3. Koul Parvaiz A, Patel Dharmesh (2015) Indian guidelines for asthma: Adherence is the key. Lung India 32(1): S1-S2.

4. Klaewsongkram J, Reantragoon R (2009) Asthma research performance in Asia-Pacific: A bibliometric analysis by searching PubMed database. Journal of Asthma 46(10): 1013-1020.

5. Gupta BM, Bala A (2011) Mapping of asthma research in India: A scientometric analysis of publications output during 1999-2008. Lung India 28(4): 239-246.

6. Sweileh WM, Al-Jabi SW, Zyoud SH, Sawalha AF (2014) Bronchial asthma and chronic obstructive pulmonary disease: research activity in Arab countries. Multidisciplinary Respiratory Medicine 9(1): 38.

7. Chen Su-Ru, Chiu Wen-Ta, Ho YS (2005) Asthma in children: mapping the literature by bibliometric analysis. Revue Françaised'Allergologieetd'Immunologie Clinique 45(6): 442-446.

8. Börger JA, Neye N, Scutaru C, Kreiter C, Puk C, et al. (2008) Models of asthma: Density-equalizing mapping and output benchmarking. Journal of Occupational Medicine and Toxicology 3(1): S7. 